\title{
Hyperlactatemia and its adverse patient outcomes among patients who underwent cardiopulmonary bypass surgery at national cardiac centre Addis Ababa, Ethiopia 2021. Retrospective observational study
}

Tigist Tesfaye

Addis Ababa University

Getaneh Baye Mulu

Debre Berhan University

Bantalem Tilaye Atinafu

Debre berhan university

Fetene Nigussie Tarekegn

Debre Berhan University

Worku Misganaw kebede ( $\square$ wmisganaw2016@gmail.com )

Debre Berhan University

\section{Research Article}

Keywords: Hyperlactatemia, Associated factors, Adverse outcomes, National cardiac center

Posted Date: October 7th, 2021

DOI: https://doi.org/10.21203/rs.3.rs-651580/v1

License: (9) (1) This work is licensed under a Creative Commons Attribution 4.0 International License.

Read Full License 


\section{Abstract}

Background: Hyperlactatemia and lactic acidosis are commonly encountered during and after cardiac surgery. Hyperlactatemia is highly suggestive of tissue ischemia and is associated with a prolonged intensive care unit stay, a prolonged requirement for respiratory and cardiovascular support, and increased postoperative mortality.

Objective: To assess hyperlactatemia and adverse outcomes among patients who underwent cardiopulmonary bypass surgery at Cardiac Center Ethiopia, Addis Ababa, Ethiopia, 2021.

Method: An institution-based retrospective cross-sectional study was employed among all patients who underwent cardiopulmonary bypass surgery from December to January 2020. Blood lactate samples were collected intraoperatively and postoperatively. We entered the collected data into Epidata version 4.2 and export it to SPSS 25 for analysis. We did descriptive statistics for categorical and continuous variables and chi-square to show an association between the outcome variable and independent variables. We entered variables fitted in bivariate analysis into multivariable analysis to show the strength of the association and the statistically significant variable.

Result: The prevalence of hyperlactatemia in this study among patients who underwent cardiac surgery procedures at Cardiac Center Ethiopia was $37.5 \%$. A rise in lactate level prolongs ICU stay, prolongs intubation duration, and increases the need for Inotropes support. Lactate level was measured on the immediate postoperative day within 10 hours after the surgery and was defined as lactate level $>3$ $\mathrm{mmol} / \mathrm{L}$ in the first hour after surgery. Age $>40$ years [AOR: $6.8(95 \% \mathrm{Cl} 1.7-25), \mathrm{P}=<0.008$ ]. female gender [AOR: $1.8(95 \% \mathrm{Cl} 1.1-3.8), \mathrm{P}=0.048$ ]. Variables statistically significant were declared at $95 \% \mathrm{Cl}, \mathrm{p}$-value $<$ 0.05 .

Conclusion and Recommended: An early rise in lactate levels in patients who underwent cardiopulmonary bypass surgery is a strong and robust predictor of morbidity. As a result, screening of patients in the preoperative period and strict follow-up management of those factors is recommended.

\section{Background}

Hyperlactatemia and lactic acidosis regularly experienced during and after heart medical and surgical procedures. Perioperative lactate creation increments in the myocardium, skeletal muscle, lungs, and, splanchnic dissemination during the cardiopulmonary surgeries. Hyperlactatemia has a bimodal circulation in the Perioperative Period. An early expansion in lactate levels, emerging intra-operatively or not long after the emergency unit, is a recognizable and concerning finding for most clinicians. It is profoundly reminiscent of tissue ischemia related to a delayed emergency unit, a drawn-out prerequisite for respiratory and cardiovascular help, and expanded postoperative mortality (1).

During a cardiovascular surgical procedure, patients giving late cresting blood lactate postoperative state are at expanded danger for helpless ICU result and mortality. Tenacious pinnacle level of lactate is a 
superior marker of forecast when contrasted and transitory pinnacle lactate in post-CPB patients. The tirelessness of hyperlactatemia is a more significant determinant of postoperative patient outcomes(2). Postoperative hyperlactatemia and lactic acidosis in cardiovascular medical procedure patients are critical markers to identify undesired results in $6 \mathrm{hrs}$. Postoperative lactate level can anticipate the length of stay in ICUs and the prospect of creating adverse results and morbidity(3).

The preoperative status of the patients, alongside the explicit sedative, procedural, and postoperative elements, will result in serious short-term, long-term morbidity and mortality. The Surrogate markers of tissue perfusion are such as central venous oxygen saturation and blood lactate. More considerable differences in lactate level after CPB would be related to a prolonged ICU span and the occurrence of postoperative genuine undesired outcomes. Various studies uncovered that an intraoperative increment in lactate level is an inherent and explicit indicator of patients at high risk for morbidity and mortality after operations for congenital cardiac disease. The rise in in the lactate level during the cardiopulmonary bypass and the possible predictive value in identifying patients at high risk of morbidity and mortality after surgery for cardiac disease(4).

The persistence of hyperlactatemia is a more critical determinant of postoperative outcome than the absolute value of the peak lactate concentration. Blood lactate concentration level ranging from $>2$ $\mathrm{mmol} / \mathrm{L}$ to $10 \mathrm{mmol} / \mathrm{L}$ mild to severe form during CPB identifies a subgroup of patients with increased risk of varying degree of postoperative morbidity and mortality. Another study defines hyperlactatemia defined as lactate level $>3 \mathrm{mmol} / \mathrm{L}$ in the first hour after surgery(5). Postoperative hemodynamic instability occurred in $29.5 \%$ of patients with elevated lactate levels during CPB, contrasted with $10.9 \%$ of patients with lower lactate levels. Postoperative mortality was $11 \%$ higher when it is determined with patients who had peak blood lactate levels of less than $4.0 \mathrm{mmol} / \mathrm{L}$ during CPB.(6-8).

It distinct that postoperative dismalness irregular in patients going through a cardiovascular procedure. More than $66 \%(70.2 \%)$ of patients had at least one major complication. With the most regularly happening intricacy was low cardiac output state (29.8\%), trailed by renal dysfunction $(25.4 \%)$, mechanical ventilation (15.7\%), and atrial fibrillation (14.6\%). Almost one-fourth (23.2\%) of the patients remained in the ICU for $>2$ days, and LOS in the emergency room was for $>7$ days for particularly over $60 \%$ of the patients(9).

Postoperative mortality was higher among patients with lactate levels over $4 \mathrm{mmol} / \mathrm{L}$ on ICU admission $(18.7 \%$ versus $6.2 \%)$ when contrasted and the individuals who have under $4 \mathrm{mmol} / \mathrm{L}(10)$. This study Aims to assess the magnitude and associated factors of hyperlactatemia among patients who underwent cardiopulmonary bypass surgery at Cardiac Center Ethiopia Addis Ababa, Ethiopia, 2021.

\section{Methods And Materials}

\section{Study design, population, and setting}


We employed a retrospective, cross-sectional documentary review among all patients who underwent open-heart surgery from February 2009 to October 2020. This study was conducted from December 2020 to February 2021 at Cardiac Center Ethiopia; Cardiac Center Ethiopia is the first cardiac center in Ethiopia inaugurated on February 12, 2009. This nonprofit Center specializes in heart disease and is especially committed to helping children with cardiac problems. The center performs all cardiac surgeries for rheumatic, valvular, and congenital heart disease for infants, children, adolescents, and adults by a qualified Ethiopian team, operating on various cardiac surgical interventions with two fully dedicated operation theatres, $10 \mathrm{ICUs}$ beds, and two functional cath-lab machines.

\section{Eligibility criteria}

\section{Inclusion criteria}

All selected registered and complete patients who underwent cardiopulmonary bypass surgery.

\section{Exclusion criteria}

Missed and incomplete patient charts were excluded from the study

\section{Sample Size determination}

The sample size for the study was determined by using a single population formula by using a $95 \%$ confidence interval $50 \%$ population proportion and a $5 \%$ margin of error.

$\mathrm{n}=\mathrm{Za} / 2 \times \mathrm{p}(\mathrm{q}) / \mathrm{d}^{2}=(1.96)^{2} \times 0.5(0.5) /(0.05)^{2}=384$

Since the study population is less than 10,000 , sample size reduction was used.

$\mathrm{Nf}=\mathrm{ni} / 1+\mathrm{ni} / \mathrm{N}$

Where: $-\mathrm{nf}=$ final Sample Size

ni= initial Sample Size

$\mathrm{N}=$ total population

$\mathrm{nf}=384 / 1+384 / 1149$

$\mathrm{nf}=384 / 1.3$

$\mathrm{nf}=259.34$

$n f=296$

After adding $10 \%$ non-response rate the final sample size was 329 .

\section{Sampling procedure and Techniques}


The required sample size was selected systematically every three intervals by using the Medical Record Number (MRN) from Health Service Management and Information System (HMIS) of patients as a sampling frame.

\section{Study Variables \\ Dependent variable}

The magnitude of lactate level

\section{Independent Variables}

Age, Sex, Co-morbidities (Diabetes, hypertension), Drugs (Anti-diabetes medications, Anti-hypertensive medications, Heparin, Anti-platelet), Preoperative SBP, Preoperative DBP, NYHA class HF, Presence of MI, Previous cardiac surgery, Presence of Stroke, Cardioplegia type (Del Nido, Cold blood), Haemoglobin level, Glucose level, Atrial fibrillation, Operation category (Isolated CABG, Isolated valves, Combined, Others).

\section{Intraoperative variables}

- Cross Clamp time (min), Duration of CPB (min), PO2 level (mmHg).

\section{Data collection tools and procedures}

we adapted the data collection tool (questionnaire) from the previous studies. (11)(15),(12),19).The tools consisted of checklists prepared in the English version and had five parts (Socio-demographic characteristics, clinical or biochemical characteristics, comorbidities, drugs and intra-operative variables). We reviewed the cardiac patient's chart retrospectively by using the data collection checklist. The data collectors and supervisor were from the center. The data collection procedure was review of medical chart. Detailed review was done on the systematically selected patient charts. The serum lactate level was measured during the intra-operative period and postoperatively within 12 hours since serum lactate level will be peak during this period. For analysis the average of intra-operative and postoperative lactate was used.

\section{Operational definitions}

Outcome $=$ patients with elevated blood lactate level measure $>3 \mathrm{mmol}$.

Adverse outcomes: - intubation more than 24 hours, ICU stay more than three days

\section{Data Quality Assurance}

The one-day training was given for 3 data collectors and one supervisor before data collection To assure the quality of the data. The questionnaire carefully designed, and the English version used for data collection. Before the actual data collection time, the questionnaire checked for clarity and comprehensiveness. During data collection, the supervisor had monitored the data collection process by 
checking the data's completeness and making corrections on the site of data collection when any problem happened. The principal investigator has reviewed data for its completeness during data entry and the cleaning process.

\section{Data processing and analysis}

The data were collected from the medical records of patients who underwent cardiac surgery under CPB. Epi data version 4.2 was used for data entry and recording; cleaning and analysis was done with SPSS version 23. We calculated descriptive statistics such as frequencies, proportions, means, and Standard deviations. Adverse postoperative outcomes secondary to hyperlactatemia were assessed. The bivariate analysis was used to determine the relationship between each independent variable and the lactate level. Variables that were considered as significantly associated at $p$-value $<0.25$ in the bivariate analysis were entered into the multivariable analysis logistic regression model. Finally, the variables which had significant association were identified on the basis of the odds ratio (OR), with $95 \% \mathrm{Cl}$. The finding expressed with $95 \% \mathrm{Cls}$, and a significant variable was declared at $\mathrm{p}<0.05$, which was statistically significant.

\section{Results}

\section{Socio-demographic and clinical characteristics}

A total of 1149 patients who underwent cardiopulmonary bypass surgery at Cardiac Center Ethiopia from these 326 samples were systematically selected. Two hundred ninety-seven were complete charts, 23 were incomplete and replaced by other charts. Finally, we reviewed 320 complete patient charts for this study. It gives the response rate (the completeness rate of $98.1 \%$ ). Their mean age was [23.5 \pm 14.8$]$ years, and 188 were females (58.8\%). Inotrope and Vasopressor Support Ventricular and vascular dysfunction are pervasive post-cardiac surgery, and most patients need inotropic or vasopressor support after separation from bypass. In this study, nearly two-thirds of $195(60.9 \%)$ of the study participants supported inotropes or vasopressors. (Table1).

The immediate postoperative period of most cardiac surgery is correlated with hemodynamic liabilities and un-stabilities which are typical early postoperative complications. Monitoring those hemodynamic measuring parameters in the entire course is crucial for predicting patient outcomes and prognosis. In this study, the study subjects' hemodynamic status data shown as follows. Above half of the study, subjects used the Del-Nido cardioplegia 189 (53.4\%) and 180 (56.2\%) patients Glucose level was 126200. (Table 2)

Different types of cardiac surgeries will be selected and applied based on the patient's disease condition, types of illness, age, and presence of comorbidities. In this study, three types of operative categories underwent. Valve replacement accounts for 189(59.1\%), congenital heart disease surgery $104(32.5 \%)$.

(Figure 1) 
During open-heart surgeries, intersecting the blood flow through the aorta by applying a cross-clamp is often an essential step to permit surgical repair. The mean cross-clamp time for the study subjects is 84 \pm 46.9 minutes. An extended period of cross-clamp time commonly a risk factor for significant postoperative morbidity and mortality. In this study, $<60$ minutes in 115 patients $35.9 \%, 60-90$ minutes in 89 patients $27.8 \%$, and $>90$ minutes in 116 patients $36.3 \%$. A significantly increased cross-clamp time is a predictor of mortality, increased need for inotropes, prolonged intensive care unit stay, and complex adverse outcomes (Figure 2)

\section{The magnitude and Adverse outcomes of Hyperlactatemia}

This study assessed the magnitude of hyperlactatemia showed a higher prevalence of $37.5 \%$ (95 $\mathrm{Cl} 27.1$ 48.9.1). The outcome after any heart surgery is determined by the patient's pre-existing symptoms and intraoperative factors. These various factors contribute to the development of hyperlactatemia and the effect of undesirable postoperative outcomes for patients. In this study, hyperlactatemia adversely affects patient outcomes and prognosis. ICU stay adversely affected by a rise in lactate level. Patients with elevated lactate stay in ICU longer durations when compared with those with low lactate level [(74\% versus $47 \%), P=0.000$ ]. Besides, patients with elevated lactate levels also need more ionotropic drug use when compared with their counterparts [(66.6\% versus $57.7 \%), P=0.000)$. Likewise, lactatemia increases the duration of intubation than those who had average lactate level [( $85 \%$ versus $47 \%), P=0.000)$. (Table 3)

\section{Associated factors of hyperlactatemia among patients who underwent cardiopulmonary bypass surgery}

A logistic regression model was used to evaluate the independent predictor's hyperlactatemia. First, a bivariable logistic regression model was done to screen potential candidate variables for multivariable logistic regression. Variables with a $P$-value of $<0.25$ were included in a multivariable logistic regression model. After conducting bivariate analysis, variables like age, sex, systolic BP, diastolic BP, glucose level, Hemoglobin level, Heparin, Atrial fibrillation, anti-platelet drugs, and operative category entered to multivariable analysis for further analysis.

Variables having a statistically significant association in multivariable logistic regression were older age and female gender with hyperlactatemia.

The odds of hyperlactatemia among patients who underwent cardiopulmonary bypass surgery patients age $>40$ years were 6.8 times higher compared with those $\leq 50$ years of age [AOR: $6.8(95 \% \mathrm{Cl} 1.7-25), \mathrm{P}=$ $<0.008]$. Similarly, the odds of developing hyperlactatemia among female patients who underwent cardiopulmonary bypass surgery is 1.8 times higher when compared with their counterparts [AOR: 1.9 (95\% Cl 1.1-3.8), $\mathrm{P}=0.048]$. (Table 4)

\section{Discussion}


In most open-heart surgeries, hyperlactatemia can arise from different factors. It can be secondary to a hypoxic state or non-hypoxic. Several studies showed that postoperative hyperlactatemia worsened patient outcomes and more extended hospital stay.

Various factors contribute to the development of hyperlactatemia and undesirable postoperative outcomes for patients. In this study, hyperlactatemia adversely affects patient outcomes. ICU stay adversely affected by elevated lactate level. Patients with elevated lactate stay in ICU longer durations when compared with those with low lactate level [(74 \% versus $47 \%), P=0.000]$. This is supported by different studies longer ICU stay $(P=0.013)$ was found to be the result of an elevated level of lactate in the blood(13)(18). Another study also supported that Patients with hyperlactatemia had suggestively higher rate of prolonged intubation time with mechanical ventilator, prolonged hospital stay and more inotrope support required(14)

Besides this, patients with elevated lactate levels also need more ionotropic drug use when compared with their counterparts [(66.6\% versus $57.5 \%), P=0.000)$. this is in line with other studies ( $34 \%$ vs $11.8 \% ; P$ $=0.001)$. Some surgeries require the patient to be on the ventilator for a short time after surgery as part of the plan. But patients with hyperlactatemia may need prolonged respiratory support with a ventilator. In this study, patients with hyperlactatemia has a longer duration of intubation than their counterparts. Hyperlactatemia increases the duration of intubation than those who had normal lactate levels [ $85 \%$ versus $47 \%), P=0.000)(12)(15)(18)$.

The magnitude of hyperlactatemia varies according to the timing of lactate measurement. In this study was $37.5 \%$, relatively high, which is not in line with when compared studies conducted in Egypt, which is $26 \%$ (5) But, comparable to a study conducted in Circolo Hospital, University of Insubria, Varese, Italy(14). Inconsistencies in the magnitude of lactate level may be due to the difference in the geography and timing of lactate measurement.

The difference in lactate level among males and females after open heart surgery is uncertain, but different studies showed gender differences in morbidity and mortality after patients underwent openheart surgeries. In this study, females have a 1.8 times higher chance of developing hyperlactatemia when compared with their counterparts. This is supported by studies conducted in Peking Union Medical College China(16).

Risks of hyperlactatemia and prolonged hospital stay in older adults is common. In this study, patients above 40 years of age had a higher chance of developing higher lactate levels when compared with those who are less than 50 years of age. Due to metabolic changes, as age increases, the risk of an increase in lactate also increases. This is in line with a study done in US America(17)

\section{Strength and Limitation of the study}

This study has some limitations. This observational national centre retrospective study makes it susceptible to inherent selection and information biases. Besides important variables like infections, 
some comorbidities were not registered.

The strength of the study is we have tried to assess important adverse outcomes of hyperlactatemia. We have attempted to use rigorous statistical regression analysis to control for confounders; however, I admit that adverse effects and regression analysis account for known confounders included in the multivariable model and do not account for unknown or unmeasured confounders.

\section{Conclusion}

Early rise in lactate level in patients who underwent cardiopulmonary bypass surgery is a strong and robust predictor of morbidity and undesired patient outcomes: different patient and operative factors involved in this pathophysiology

\section{Declarations}

\section{Consent for publication}

It is to request that the submitted manuscript entitled respectfully; Hyperlactatemia and its adverse patient outcomes among patients who underwent cardiopulmonary bypass surgery at national cardiac centre Addis Ababa, Ethiopia 2021. Retrospective observational study" is considered for publication Research square. We prepared This manuscript based on original and unpublished research work. All authors of this research paper had directly participated in the analysis and interpretation of data or writing of the manuscript, have read and approved the final version of the submitted manuscript. None of the authors had any intellectual or financial conflicts of interest. The contents of this manuscript have not been copyrighted or published previously and are not now under consideration for publication elsewhere. The contents of this manuscript will not be copyrighted, submitted, or published elsewhere while acceptance by the research square is under consideration.

\section{Ethical consideration}

We obtained ethical clearance for the proposed study from the Addis Ababa university Tikur Anbessa hospital research and ethics committee. A letter of cooperation was written to the national cardiac center and concerned bodies. Consent obtained from the medical director and focal person of cardiac center. Confidentiality of the information was kept throughout the study by excluding names and we used patient record numbers as identification in the data extraction form and the data only for the proposed research. All collected data were coded and locked in a separate room before entering into the computer to keep the confidentiality. After entering the computer, the data were locked by password, and the data was not disclosed to any person other than the principal investigators.

\section{Competing interest}

Authors declared that there is no competing interest. 
Availability of data and materials

Data support these findings are contained within the manuscript and will share upon request to the corresponding author.

\section{Funding body}

No funding bodies.

\section{Authors' contribution}

All authors conceptualized the study and detailed design, analysis, interpretation, report, and manuscript writing. TT, FN, BT, and WK made a substantial contribution to conception and design, analysis and interpretation of data, drafting the manuscript, and critical revision for important intellectual content. All the authors read and approved the final manuscript.

\section{Acknowledgments}

First, we would like to express our deepest gratitude and appreciation to Addis Ababa university college of medicine for its willingness to permit us to conduct this study. Finally, we would like to acknowledge national cardiac center nurses and registration room officers for their kind cooperation during the data collection period.

\section{Abbreviations}

AOR

adjusted odds ratio

$\mathrm{BP}$

Blood pressure

CABG

coronary artery bypass graft

COR

crude Odds ratio

$\mathrm{Cl}$

Confidence interval

CVD

Cardiovascular disease

DBP

Diastolic blood pressure

HMIS

health information management system

MRN

medical registration number 
Systolic blood pressure

\section{References}

1. O'connor E, Fraser J. The interpretation of perioperative lactate abnormalities in patients undergoing cardiac surgery. Anaesthesia and intensive care. 2012;40(4):598-603.

2. Mak NT, Iqbal S, de Varennes B, Khwaja K. Outcomes of post-cardiac surgery patients with persistent hyperlactatemia in the intensive care unit: a matched cohort study. Journal of Cardiothoracic Surgery. 2016;11(1):33.

3. Alam JM, Hussain A, Ali HH, Asghar SS, Riaz S. Study on Significant Correlation of Postoperative Hyperlactatemia with Poor Prognosis in Cardiac Surgery Patients. International Journal of Pharma Research and Health Sciences. 2016;4(5):1225-8.

4. Munoz R, Laussen PC, Palacio G, Zienko L, Piercey G, Wessel DL. Changes in whole blood lactate levels during cardiopulmonary bypass for surgery for congenital cardiac disease: an early indicator of morbidity and mortality. The Journal of thoracic and cardiovascular surgery. 2000;119(1):155-62.

5. Algarni KD. The effect of hyperlactatemia timing on the outcomes after cardiac surgery. The Cardiothoracic Surgeon. 2020;28(1):18.

6. Demers P, Elkouri S, Martineau R, Couturier A, Cartier R. Outcome with high blood lactate levels during cardiopulmonary bypass in adult cardiac operation. The Annals of thoracic surgery. 2000;70(6):2082-6.

7. Rishu AH, Khan R, Al-Dorzi HM, Tamim HM, Al-Qahtani S, Al-Ghamdi G, et al. Even mild hyperlactatemia is associated with increased mortality in critically ill patients. Critical care (London, England). 2013;17(5):R197.

8. Khosravani H, Shahpori R, Stelfox HT, Kirkpatrick AW, Laupland KB. Occurrence and adverse effect on outcome of hyperlactatemia in the critically ill. Critical care (London, England). 2009;13(3):R90.

9. Patra C, Gatti PC, Panigrahi A. Morbidity After cardiac surgery under cardiopulmonary bypass and associated factors: A retrospective observational study. Indian heart journal. 2019;71(4):350-5.

10. Noval-Padillo J, Serra-Gomez C, Gomez-Sosa L, Hinojosa-Perez R, Huici-Moreno M, Adsuar A, et al., editors. Changes of lactate levels during cardiopulmonary bypass in patients undergoing cardiac transplantation: possible early marker of morbidity and mortality. Transplantation proceedings; 2011 : Elsevier.

11. Ranucci M, Toffol BD, Isgrò G, Romitti F, Conti D, Vicentin M. Hyperlactatemia during cardiopulmonary bypass: determinants and impact on postoperative outcome. Critical Care 2006;10:R167

12. Toraman F, Evrenkaya S, Yuce M, Aksoy N, Karabulut H, Bozkulak Y, et al. Lactic Acidosis after Cardiac Surgery Is Associated with Adverse Outcome. The Heart Surgery Forum \#2004-1002. 2004;7 (2), 2004 [Epub March 2004]. 
13. Naik R, George G, Karuppiah S, Philip MA. Hyperlactatemia in patients undergoing adult cardiac surgery under cardiopulmonary bypass: Causative factors and its effect on surgical outcome Ann Card Anaesth 2016:19:668-75.

14. Matteucci M, Ferrarese S, Cantore C, Cappabianca G, Massimi G, Mantovani V, et al. Hyperlactatemia during cardiopulmonary bypass: risk factors and impact on surgical results with a focus on the longterm outcome. Perfusion. 2020;35(8):756-62.

15. Naik R, George G, Karuppiah S, Philip MA. Hyperlactatemia in patients undergoing adult cardiac surgery under cardiopulmonary bypass: Causative factors and its effect on surgical outcome. Ann Card Anaesth. 2016;19(4):668-75.

16. Fu SP, Zheng Z, Yuan X, Zhang SJ, Gao HW, Li Y, et al. Impact of off-pump techniques on sex differences in early and late outcomes after isolated coronary artery bypass grafts. Ann Thorac Surg. 2009;87(4):1090-6.

17. Madhavan MV, Gersh BJ, Alexander KP, Granger CB, Stone GW. Coronary Artery Disease in Patients $\geq 80$ Years of Age. Journal of the American College of Cardiology. 2018;71(18):2015-40.

\section{Tables}

Table 1: Socio-demographic and Co-morbidity characteristics of patients who underwent cardiopulmonary bypass surgery at Cardiac Center Ethiopia, Addis Ababa, Ethiopia, February 2021. 


\begin{tabular}{|c|c|c|c|}
\hline Characteristics & $N=320$ & Freq. & Percent \\
\hline \multirow[t]{2}{*}{ Lactate } & $\leq 3 \mathrm{mmol} / \mathrm{l}$ & 200 & 62.5 \\
\hline & $>3 \mathrm{mmol} / \mathrm{l}$ & 120 & 37.5 \\
\hline \multirow[t]{2}{*}{ Sex } & Male & 132 & 41.2 \\
\hline & Female & 188 & 58.8 \\
\hline \multirow[t]{5}{*}{ Age in years } & $\leq 10$ yrs & 47 & 14.7 \\
\hline & 11-20yrs & 128 & 40 \\
\hline & 21-30yrs & 74 & 23.1 \\
\hline & 31-40yrs & 37 & 11.6 \\
\hline & $41 y r s$ & 34 & 10.6 \\
\hline \multirow[t]{2}{*}{ Diabetes } & Yes & 3 & 0.9 \\
\hline & No & 217 & 99.1 \\
\hline \multirow[t]{2}{*}{ Hypertension } & Yes & 5 & 1.6 \\
\hline & No & 315 & 98.4 \\
\hline \multirow[t]{2}{*}{ Heart failure } & Yes & 24 & 7.5 \\
\hline & No & 296 & 92.5 \\
\hline \multirow[t]{2}{*}{ Myocardial infarction } & Yes & 1 & 0.3 \\
\hline & No & 319 & 99.7 \\
\hline \multirow[t]{2}{*}{ Previous cardiac surgery } & Yes & 2 & 0.6 \\
\hline & No & 318 & 99.4 \\
\hline \multirow[t]{2}{*}{ Atrial fibrillation } & Yes & 46 & 14.4 \\
\hline & No & 274 & 85.6 \\
\hline \multirow[t]{2}{*}{ ICU stays } & $\leq 72$ & 175 & 54.7 \\
\hline & $>72$ & 145 & 45.3 \\
\hline \multirow[t]{2}{*}{ Intubation duration } & $\leq 24$ & 120 & 37.5 \\
\hline & $>24$ & 200 & 62.5 \\
\hline \multirow[t]{2}{*}{ Inotropes } & Yes & 195 & 60.9 \\
\hline & No & 125 & 39.1 \\
\hline
\end{tabular}


Table 2: Operative and hemodynamic status of patients who underwent Cardiopulmonary bypass surgery at Cardiac Center Ethiopia, Addis Abeba, Ethiopia, February 2021.

\begin{tabular}{|llll|}
\hline Variables & Characteristics & Freq. & Percent \\
\hline Cardioplegia type & Del-Nido & 189 & 53.4 \\
\cline { 2 - 4 } Hemoglobin level & Cold blood & 131 & 46.6 \\
& $\leq 11.5 \mathrm{~g} / \mathrm{dl}$ & 62 & 19.4 \\
\cline { 2 - 4 } Systolic Blood pressure & $>11.5 \mathrm{~g} / \mathrm{dl}$ & 258 & 81.6 \\
& $\leq 90 \mathrm{mmHg}$ & 50 & 15.6 \\
\cline { 2 - 4 } & $90 \mathrm{mmHg}$ & 270 & 84.4 \\
\hline Diastolic blood pressure & $\leq 60 \mathrm{mmHg}$ & 140 & 43.8 \\
\cline { 2 - 4 } & $>60 \mathrm{mmHg}$ & 180 & 56.2 \\
\hline Glucose level & $<126 \mathrm{~g} / \mathrm{dl}$ & 108 & 33.8 \\
\cline { 2 - 4 } & $126-200 \mathrm{~g} / \mathrm{dl}$ & 180 & 56.2 \\
\cline { 2 - 4 } & $>200 \mathrm{~g} / \mathrm{dl}$ & 32 & 10 \\
\hline CBP time & $\leq 180 \mathrm{~min}$ & 276 & 86.2 \\
\cline { 2 - 4 } & $>180 \mathrm{~min}$ & 44 & 13.8 \\
\hline P02 level & $<150$ & 47 & 14.7 \\
& $\geq 150$ & 273 & 85.3 \\
\hline & & & \\
& & &
\end{tabular}

Table 3 Adverse outcomes Associated with hyperlactatemia patients who underwent cardiopulmonary bypass surgery at Cardiac Center Ethiopia, Addis Ababa, Ethiopia, February 2021. 


\begin{tabular}{|c|c|c|c|c|c|}
\hline \multirow[t]{2}{*}{ Adverse outcomes } & \multirow[t]{2}{*}{ Classifications } & \multicolumn{2}{|c|}{ Lactate level } & \multirow{2}{*}{$\begin{array}{l}\text { Chi-square } \\
\text { correlation }\end{array}$} & \multirow[t]{2}{*}{ Comparisons } \\
\hline & & $\leq 3 \mathrm{mmol} / \mathrm{l}$ & $>3 \mathrm{mmol} / \mathrm{I}$ & & \\
\hline \multirow[t]{2}{*}{ ICU stays } & $\leq 72 \mathrm{hrs}$ & 106 & 39 & & \multirow{2}{*}{$\begin{array}{l}74 \% \text { vs } 47 \\
\%\end{array}$} \\
\hline & $>72$ hrs. & 94 & 81 & 0.000 & \\
\hline \multirow{2}{*}{$\begin{array}{l}\text { Prolonged } \\
\text { intubation }\end{array}$} & $\leq 24 \mathrm{hrs}$ & 196 & 4 & & \multirow[t]{2}{*}{$85 \%$ vs $47 \%$} \\
\hline & $>24 \mathrm{hrs}$ & 86 & 34 & 0.000 & \\
\hline \multirow[t]{2}{*}{$\begin{array}{l}\text { lonotropic drug } \\
\text { use }\end{array}$} & Yes & 115 & 80 & 0.000 & \multirow[t]{2}{*}{$\begin{array}{l}66.6 \% \text { vs } \\
57.5 \%\end{array}$} \\
\hline & No & 85 & 40 & & \\
\hline
\end{tabular}

Table 4 Bi-variable and multivariable logistics regression of factors associated with hyperlactatemia at Cardiac Center Ethiopia, Addis Ababa, Ethiopia, February 2021. 


\begin{tabular}{|c|c|c|c|c|c|}
\hline \multirow[t]{2}{*}{ Variables } & \multirow[t]{2}{*}{ Characteristics } & \multicolumn{2}{|c|}{ Hyperlactatemia } & \multirow[t]{2}{*}{ COR 95\% Cl } & \multirow[t]{2}{*}{ AOR $95 \% \mathrm{Cl}$} \\
\hline & & Yes & No & & \\
\hline \multirow[t]{2}{*}{ Diastolic BP } & $\leq 60 \mathrm{mmHg}$ & 58 & 82 & $1.4(1.1-2.4)$ & $1.8(1.2-3.9)$ \\
\hline & $>60$ & 62 & 118 & 1 & 1 \\
\hline \multirow[t]{2}{*}{ Systolic BP } & $<90$ & 22 & 28 & $1.1(0.5-2.4)$ & $1(0.4-2.5)$ \\
\hline & $\geq 90$ & 98 & 172 & 1 & 1 \\
\hline \multirow[t]{2}{*}{ Sex } & Male & 60 & 72 & 1 & 1 \\
\hline & Female & 60 & 128 & $2.2(1.2-4)$ & $1.8(1.1-3.8)$ * \\
\hline \multirow[t]{5}{*}{ Age } & $\leq 10$ & 14 & 33 & 1 & 1 \\
\hline & $11-20$ & 55 & 73 & 2.6(1.1-7.9) & $2.6(0.8-8.4)$ \\
\hline & $21-30$ & 20 & 54 & $1(0.5-3.6)$ & $1.1(0.3-4.8)$ \\
\hline & $31-40$ & 13 & 24 & $3(1.2-10)$ & $3.8(0.9-12.5)$ \\
\hline & $>40$ & 18 & 16 & $5.1(3.0-15)$ & $6.8(1.7-25)$ * \\
\hline \multirow[t]{2}{*}{ Atrial fibrillation } & Yes & 14 & 32 & $0.6(0.2-1.5)$ & $0.6(0.2-1.4)$ \\
\hline & No & 106 & 168 & 1 & 1 \\
\hline \multirow[t]{2}{*}{ Heparin } & Yes & 17 & 20 & $1.7(0.8-3.8)$ & $2(0.8-5.2)$ \\
\hline & No & 103 & 180 & 1 & 1 \\
\hline \multirow[t]{2}{*}{ Anti-platelet } & Yes & 3 & 1 & $1.7(0.6-5.6)$ & $2.1(0.5-7.4)$ \\
\hline & No & 117 & 199 & 1 & 1 \\
\hline \multirow[t]{3}{*}{ Glucose level } & $\leq 125$ & 41 & 67 & 1 & 1 \\
\hline & $126-200$ & 61 & 119 & $0.8(0.4-1.8)$ & $0.6(0.3-1.3)$ \\
\hline & $>200$ & 18 & 14 & $1.2(0.6-3.2)$ & $1.2(0.4-3.5)$ \\
\hline \multirow[t]{2}{*}{ Hemoglobin level } & $<11.5 \mathrm{~g} / \mathrm{dl}$ & 22 & 40 & $1(0.6-2)$ & $1.8(0.7-4.3)$ \\
\hline & $\geq 11.5$ & 96 & 160 & 1 & 1 \\
\hline
\end{tabular}

Heparin

10

17

$0.9(0.4-2$.

$0.4(0.1-1.3)$ 


\begin{tabular}{|lllll|} 
Valves & 70 & 119 & $1.1(0.4-3.2)$ & $0.5(0.2-1.5)$ \\
\hline Congenital & 40 & 64 & 1 & 1 \\
\hline
\end{tabular}

\section{Note:}

* Statistically significant with P-value $\leq 0.05$,

AOR: adjusted odds ratio, BP: blood pressure, CABG: coronary artery bypass graft, COR: crude odds ratio.

\section{Figures}

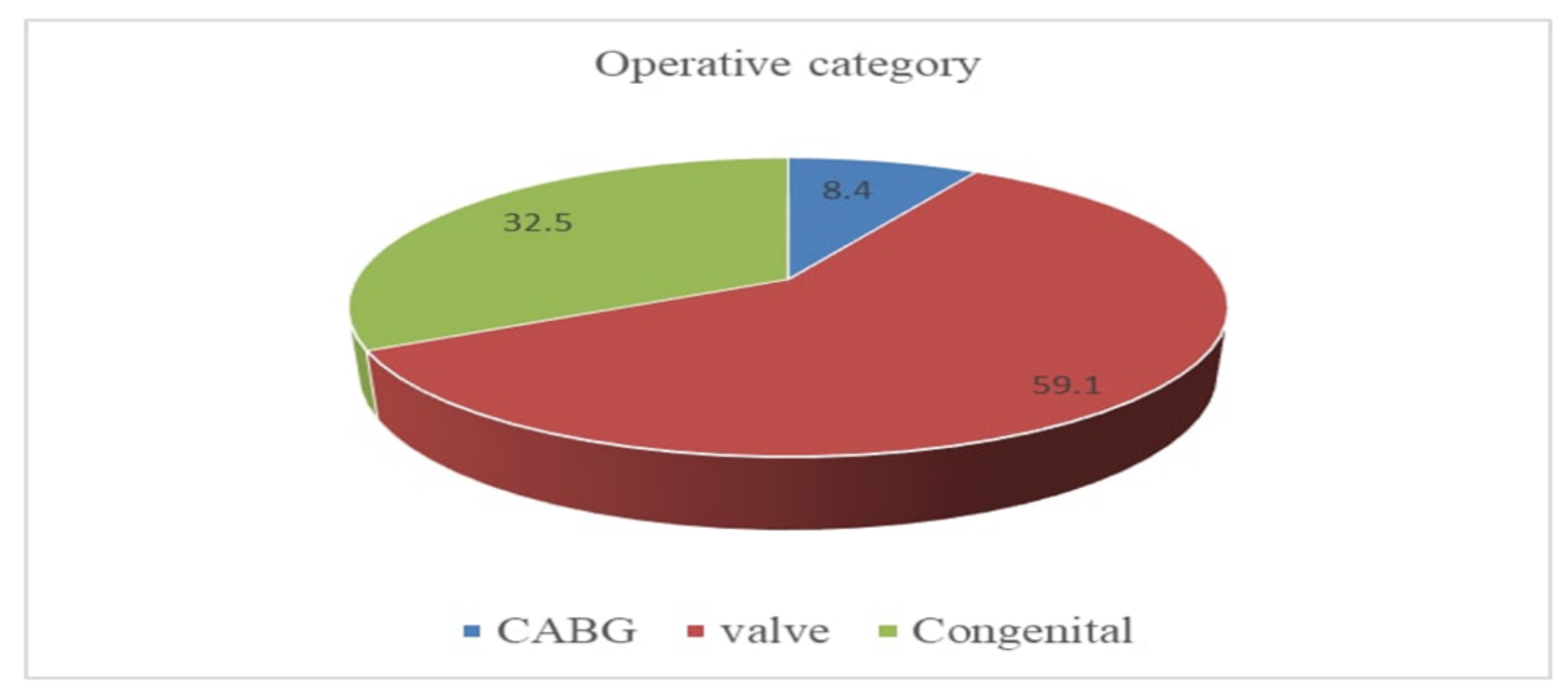

Figure 1: Showing operative categories of patients who underwent cardiopulmonary bypass surgery at Cardiac Center Ethiopia, Addis Ababa, Ethiopia, February 2021.

\section{Figure 1}

Showing operative categories of patients who underwent cardiopulmonary bypass surgery at Cardiac Center Ethiopia, Addis Ababa, Ethiopia, February 2021 


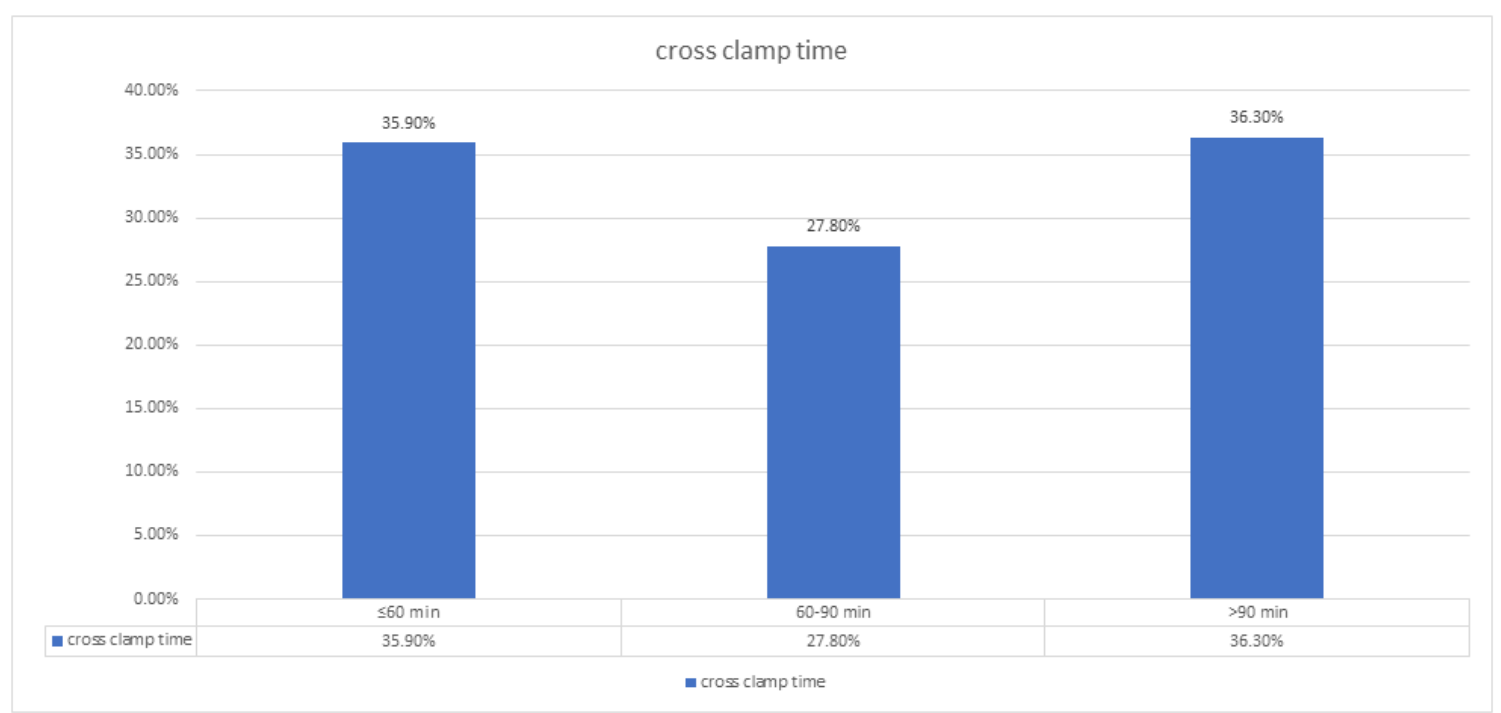

- Figure 2: Represents the cross-clamp time of patients who underwent cardiopulmonary bypass surgery at Cardiac Center Ethiopia, Addis Ababa, Ethiopia, February 2021.

\section{Figure 2}

Represents the cross-clamp time of patients who underwent cardiopulmonary bypass surgery at Cardiac Center Ethiopia, Addis Abeba, Ethiopia, February 2021. 